\title{
Effect of Free Stall Surface on Daily Activity Patterns in Dairy Cows with Relevance to Lameness Prevalence
}

\author{
N. B. Cook, T. B. Bennett, and K. V. Nordlund \\ School of Veterinary Medicine, \\ University of Wisconsin, Madison 53706-1102
}

\begin{abstract}
Differences in behavior of nonlame cows, slightly lame cows, and moderately lame cows in 6 free stall barns with sand bedding (SAND) vs. 6 free stall barns with rubber-crumb geotextile mattress surfaces (MAT) were documented in Wisconsin dairy herds. All lactating cows in the 12 herds were observed and given a locomotion score based on a 4-point scale: $1=$ nonlame, $2=$ slightly lame, $3=$ moderately lame, and $4=$ severely lame. Herd least square means $\pm \mathrm{SE}$ for prevalence of clinical lameness (locomotion scores $=3$ and 4 ) were 11.1 vs. $24.0 \pm 1.7 \%$ for herds using SAND vs. MAT surfaces, respectively. Subsets of 10 cows per herd with locomotion scores of 1 to 3 were observed via video cameras for 24-h periods. Cows in MAT herds spent more time standing in free stalls per day than cows in SAND herds. Differences in standing times were 0.73 $\mathrm{h} / \mathrm{d}$ for cows that were not lame, $2.32 \mathrm{~h} / \mathrm{d}$ for cows that were slightly lame, and $4.31 \mathrm{~h} / \mathrm{d}$ for cows that were moderately lame in MAT herds compared with equivalent cows in SAND herds. In MAT herds, the increase in time spent standing in the stall in moderately lame cows was associated with a significant reduction in stall use sessions per day, which impacted daily lying time. Although cause and effect are not clear, these findings have implications for housing, comfort, and care of cows in dairy herds with different types of free stall surfaces. (Key words: standing, lameness, sand, mattress)
\end{abstract}

Abbreviation key: MAT = rubber crumb-filled geotextile mattress free stall, SAND = sand-bedded free stall.

\section{INTRODUCTION}

During the planning and building phase of new free stall barns, herd owners are faced with a choice of stall surface, dimensions, and divider design. Surface cushion has been suggested as the most important aspect of stall design (Nordlund and Cook, 2003), and sand

Received October 31, 2003.

Accepted May 10, 2004.

Corresponding author: N. B. Cook; e-mail: nbcook@wisc.edu. has been recommended by some as an ideal stall surface for dairy cows (Bickert, 2000), with reported benefits in reducing hock trauma (Weary and Taszkun, 2000; Vokey et al., 2001). However, there are several other choices of stall surface available. A concrete surface sparsely bedded with a small amount of organic material can no longer be considered as an acceptable bed for a dairy cow. Rubber mats and mattresses have been reported to improve stall comfort (Haley et al., 2001), and there are now a growing number of different types of cow mattresses available, with rubber crumbs, air pockets, foam, or water, which may further improve cushion and lying times (Wagner-Storch et al., 2003).

Lying times on mattress surfaces of 12 to $14 \mathrm{~h} / \mathrm{d}$ have been reported (Chaplin et al., 2000a; Tucker et al., 2003), and, in controlled studies, where individual cows have equal access to different stall surface types, daily lying times and preference for loose bedded sand stalls have been reported to be poor compared with alternatives, which included deep straw bedding and soft rubber mats (Manninen et al., 2002) or a geotextile mattress and deep-bedded sawdust (Tucker et al., 2003). Clearly, stall maintenance difficulty is an issue affecting use of loose-bedded sand stalls (Cook, 2001), and there is a need to understand the effect of different stall types and divider designs on cow behavior.

Several studies have reported higher rates of lameness in free stall herds compared with tie stall herds (Wells et al., 1993; Bergsten and Herlin, 1996; Cook, 2003). This result suggests that there are differences in environmental conditions between the 2 systems that are important to the epidemiology of lameness. These may include differences in hoof hygiene, factors that influence free stall access, and differences in cow behavior relative to stall use. These factors may influence the onset of infections of the foot, such as papillomatous digital dermatitis, and also trigger claw horn lesions, commonly associated with laminitis (Cook et al., 2004). Cook (2003) found significantly lower lameness prevalence in herds using sand stalls compared with those using other types of stall surfaces, which included rubber mats and rubber crumb-filled mattresses. Stall surface and design, with associated aberrant stall use behavior, have been suggested as risk factors for the de- 
velopment of lameness (Colam-Ainsworth et al., 1989; Leonard et al., 1994). Specifically, reduced daily lying times (Leonard et al., 1996), increased total standing time on hard surfaces (Greenough and Vermunt, 1991; Singh et al., 1993a), and 'perching' with the 2 front feet on the stall platform and the rear 2 feet in the alley (Colam-Ainsworth et al., 1989; Leonard et al., 1994; Galindo and Broom, 2000; Galindo et al., 2000) are behaviors that have been associated with increased rates of lameness. The relative importance of each of these behavior patterns in different housing types may differ, and the relationship between lying and standing times in stalls and lameness remains unclear.

The aim of this study was to determine daily activity patterns for high yielding dairy cows housed in free stall barns utilizing either sand or mattresses filled with rubber crumbs as stall surfaces and either 2-row or 3 -row pen designs. In particular, it aimed to determine whether there are behavioral differences in stall usage between cows in herds with mattress stalls and cows in herds with sand stalls.

\section{MATERIALS AND METHODS}

\section{Herd Selection}

Two local hoof trimmers and 3 local veterinarians were asked to supply a list of herds that met the following criteria: herd size between 150 and 450 cows, no recent herd size expansion within the previous $12 \mathrm{mo}$, rolling herd average milk yield $>9545 \mathrm{~kg}$, regular visits by a hoof trimmer at least once a month, drive-through TMR feeding, uniform divider design throughout all pens, high group pen size of approximately 70 to 100 cows, and stocking density not to exceed 125\% (125 cows to 100 stalls) in the high yielding group of cows. From this short list, following contact with each farmer, 6 herds using sand bedding in stalls (SAND) and 6 herds using a geotextile mattress filled with rubber crumbs and bedded with an organic material such as sawdust (MAT), were visited between April 2002 and May 2003. Willing participation in the study was sought from each farmer. No visits were performed between July and October 2002 to avoid filming cows during the period of heat stress in Wisconsin, and herds were not filmed when minimum temperatures dropped below $0^{\circ} \mathrm{C}$, as the video cameras used would fail to function. Number of rows of stalls in the pen on each farm (2 or 3 row) and milking frequency (2 or 3 times/d) on each farm were equally distributed between SAND and MAT herds.

\section{Filming and Data Collection}

For the duration of one 24-h period during which no herd management practices, such as synchronized breeding programs, bST injections, and cow sorting, were performed other than milking either 2 or 3 times a day, the high yielding pen of cows (or nearest equivalent) on each farm was filmed. Pens containing only first-lactation heifers, cows that were within a few days of calving, and late lactation groups were not chosen for filming. Four Sony DCRTRV900 miniDV video cameras (Sony Corporation, New York City, NY) were mounted in the adjacent pen across the central feed alley to cover the entire high group pen in 4 zones and set to capture $1 \mathrm{~s}$ of video recording every $30 \mathrm{~s}$. Lights over the pen were left on during the night so that filming could continue for a full $24 \mathrm{~h}$.

At least $1 \mathrm{~h}$ before the start of each filming, 10 to 12 cows were color marked with spray paint in a distinctive pattern. Cows that were notably smaller or larger than the pen average, cows with overgrown feet, or cows that were obviously severely lame were rejected from the selection process. The proportion of severely lame cows in the study population was insufficient to allow analysis between herd types (15 of 464 cows in MAT herds and 4 of 576 cows in SAND herds). Dairy Herd Improvement Association records were used to record lactation number, current DIM, last recorded daily milk yield, and last predicted mature equivalent 305 -d milk yield (ME305) for each marked cow.

At a single milking during the filming period, all lactating cows in each herd, including those in the sick pen, were scored for locomotion using the 4-point system described by Cook (2003), where $1=$ nonlame, $2=$ slightly lame, $3=$ moderately lame, and $4=$ severely lame. Herd prevalence of clinical lameness was calculated for all milking cows scored (proportion of total cows scoring 3 and 4), and, in addition, the locomotion score of each color-marked cow tracked was recorded so that this could be included as a cow level fixed effect in the statistical analysis.

Dimensions of the free stalls in the high group pen were recorded. Measurements included stall length, stall width between dividers measured on center, distance from the point of the rear curb to the rear edge of the brisket board, height of the brisket board above the stall surface, height below the neck rail to the stall surface, height to the upper edge of the lower divider rail above the stall surface, and distance from the rear edge of the neck rail along a horizontal line to a point directly above the rear edge of the curb.

Using a Panasonic AG-DV2000P MiniDV editing player and Panasonic CT-2089VYD high definition color monitor (Matsushita Electric Corporation of America, Los Angeles, CA), 10 marked cows per farm were tracked continuously for the 24-h filming period, recording location (alley, stall, or milking parlor), activity (standing up, lying down, feeding, drinking), and 
time spent performing each activity (to the nearest minute). Cows observed in estrus during the filming process were removed from the study. If one cow in the first 10 monitored could not be traced for the entire 24$\mathrm{h}$ period or was observed in estrus, the complete data set from that cow was removed, and data from one of the extra identified cows were used instead, so that each herd was represented by data from a total of 10 cows.

Cow behavior data were entered into an Excel spreadsheet (Microsoft Corp., Redmond, WA), and the time spent by each cow performing each activity per day was calculated. These activities included time lying down in stall; time standing up in stall (including perching [standing with the front 2 feet on the stall platform and the rear 2 feet in the alley]); time (standing) up in alley, including drinking; time up feeding; and time up milking between departure and return to the pen. Proportions of the time spent in the pen performing each of the activities listed previously were also calculated to control for different times spent milking between herds and cows.

The number of stall use sessions performed each day was recorded. A stall use session was defined as the period beginning when the cow first touched the stall on entry until the cow left the stall and included bouts of standing and lying. Standing bouts in the stall included standing with all 4 feet on the platform and perching activity. The number of bouts of each activity was recorded along with bout length. A subset of lying activity was used to further explore differences in stall use behavior. The proportion of long lying bouts $\geq 60$ min was calculated for each cow.

\section{Statistical Analyses}

Data were analyzed using the MIXED procedure of SAS (SAS, 1999). These data were transformed, where appropriate, based on residual plots, to ensure an approximate normal distribution and to avoid heteroscedasticity. Natural log transformations were used for time up in stall, time down in stall, time up feeding, time up milking, time up in alley, number of stall use sessions, and mean duration of lying bout. A mixed effect model was created to investigate differences in cow behavior between cows in herds with different stall base types (SAND or MAT), controlling for the random effects of farm; fixed effects at the farm level including number of rows of stalls in the pen, pen stocking density, stall curb height, and herd milking frequency; and fixed effects at the cow level including individual cow parity, last DHIA recorded milk yield, DIM at the time of filming, and locomotion score of each individual cow filmed. Factors included in the class statement were farm, base, rows, milking frequency, and locomotion score of each individual cow filmed. The containment method was used to calculate degrees of freedom, which ranged from 9 to 10 for base and 102 to 106 for locomotion score, depending on the outcome considered within the model. Analysis of covariance with stepwise manual backward elimination of both random and fixed effects, which were not significant $(P>0.05)$, was used to define the model.

From the resulting model, interactions between significant effects were added in and a manual stepwise backward elimination of nonsignificant $(P>0.05)$ effects was performed. Where 3 -way interactions remained in the model, assessment of Akaike's information criterion was made with and without the interaction present. If the interaction made little improvement to the model, it was removed. The model was created with outcomes measured in both real time and by proportion of time in pen. Where the final model produced similar results between the real-time and the proportion of time in pen outcomes, the real-time outcome was retained and reported preferentially. Such was the case for all standing, lying, feeding, and milking time measurements, probably because of the symmetry of the study with equal distribution of cows and milking frequency between SAND and MAT herds.

The final model was different for each cow behavior variable, but effects that remained significant over several outcomes included base, locomotion score of each individual cow filmed, milk yield, milking frequency, pen stocking density, and several 2-way interactions between these variables, which included, in particular, an interaction between base and locomotion score. Differences recorded between least square means were based on Fisher's protected least significant difference.

Comparison of least square means herd background data between SAND and MAT herds were made using 1 -way ANOVA, and values of $P<0.05$ were considered significant with 10 degrees of freedom. Arithmetic means of all outcomes were calculated using the MEANS procedure of SAS (SAS, 1999) so that direct comparison between outcomes would be based on a 24$\mathrm{h}$ day. Where appropriate, back-transformed means of transformed outcomes were calculated and presented, along with $95 \%$ confidence limits.

\section{RESULTS}

\section{Herd Background Data}

Mean (range) dimensions for the stall designs used in the MAT herds are compared with the SAND herds in Table 1. There were no significant differences in design between the 2 groups of farms. The height of the lower divider rail above the stall surface was numerically higher in SAND herds, owing to the use of a 
Table 1. Mean (range) free stall dimensions (m) for 6 herds using mattresses (MAT) and 6 herds using sand bedding (SAND).

\begin{tabular}{llll}
\hline Stall dimension & MAT & SAND & $P$ \\
\hline Total stall length facing wall & $2.54(2.49$ to 2.64$)$ & $2.67(2.49$ to 3.15$)$ & 0.55 \\
Total stall length facing stall & $2.27(2.21$ to 2.36$)$ & $2.30(2.23$ to 2.39$)$ & 0.41 \\
Stall length from rear curb to brisket board & $1.69(1.63$ to 1.75$)$ & $1.70(1.55$ to 1.85$)$ & 0.78 \\
Stall divider placement on center (width) & $1.16(1.10$ to 1.23$)$ & $1.15(1.13$ to 1.16$)$ & 0.38 \\
Height of brisket board & $0.17(0.13$ to 0.20$)$ & 0.16 (0.10 to 0.18$)$ & 0.64 \\
Height of lower divider rail & $0.30(0.25$ to 0.34$)$ & $0.35(0.28$ to 0.53$)$ & 0.31 \\
Height below neck rail & $1.16(1.12$ to 1.21$)$ & $1.19(1.14$ to 1.24$)$ & 0.38 \\
Horizontal distance between rear curb and neck rail & $1.64(1.57$ to 1.78$)$ & $1.64(1.55$ to 1.75$)$ & 1.00 \\
Rear curb height & $0.27(0.23$ to 0.33$)$ & 0.23 (0.19 to 0.25$)$ & 0.08 \\
\hline
\end{tabular}

narrow-loop divider in one herd. All other herds used wide-loop dividers. There was also a trend for curb height to be higher for MAT herds than for SAND herds $(P=0.08)$. Curb height was included as a fixed effect in the mixed model, but it was not significant for any of the outcomes measured. Similarly, number of rows of stalls in the pen failed to remain in the final model for any outcome and was not a significant fixed effect.

Herd level descriptive data are presented in Table 2. There was no significant difference in herd size between MAT and SAND herds, with least square means of 304.7 and 297.7, respectively. Least square mean (SE) pen stocking rates with respect to number of stalls were similar at $107.8 \%$ (5.0) for MAT and $108.0 \%$ (5.0) for SAND herds. Pen size was larger in SAND herds than in MAT herds, but the difference was small and not significant $(P=0.12)$. Annual rolling herd average milk yield and mean ambient temperature at the time of the visit were not statistically significantly different between the 2 groups. There was a trend for a higher mean turnover rate in MAT herds (36.5) than in SAND herds (28.8), but this was also not significant $(P=0.09)$.

Least square mean (SE) herd lameness prevalence, determined by locomotion scoring of all milking cows,

Table 2. Least square means and SE of herd level background data for 6 herds using mattresses (MAT) and 6 herds using sand bedding (SAND).

\begin{tabular}{|c|c|c|c|c|}
\hline & MAT & SAND & $\mathrm{SE}$ & $P$ \\
\hline Herd size (no. cows) & 304.7 & 297.7 & 30.2 & 0.87 \\
\hline Cows in pen (no.) & 77.3 & 95.8 & 7.8 & 0.12 \\
\hline Stocking rate (high pen \%) & 107.8 & 108.0 & 5.0 & 0.98 \\
\hline $\begin{array}{l}\text { Rolling herd average } \\
\text { milk yield }(\mathrm{kg})\end{array}$ & 11,241 & 11,912 & 547.5 & 0.41 \\
\hline Annual turnover rate $(\%)$ & 36.5 & 28.8 & 2.9 & 0.09 \\
\hline $\begin{array}{l}\text { Mean ambient visit } \\
\text { temperature }\left({ }^{\circ} \mathrm{C}\right)\end{array}$ & 7.2 & 8.3 & 0.4 & 0.73 \\
\hline $\begin{array}{l}\text { Herd prevalence } \\
\text { of clinical lameness }{ }^{1} \\
(\% \text { all milking cows })\end{array}$ & 24.0 & 11.1 & 1.7 & $<0.001$ \\
\hline
\end{tabular}

${ }^{1}$ Clinical lameness includes cows that had locomotion scores of 3 and 4 and were either moderately or severely lame. Locomotion score scale: 1 = nonlame, 2 = slightly lame, 3 = moderately lame, $4=$ severely lame. was significantly $(P<0.001)$ higher in MAT herds $(24.0 \% ; 1.7)$ compared with SAND herds $(11.1 \%$; 1.7$)$.

There were no significant differences for parity, DIM at the day of visit, last DHIA recorded daily milk yield, and last DHIA recorded ME305 milk yield between cows selected for filming in SAND herds, and those selected in MAT herds (Table 3).

\section{Daily Time Budgets-Base Effect}

Mean (back-transformed mean; 95\% confidence limits) daily activity time budgets for cows in MAT herds and cows in SAND herds are given in Table 4. There was no significant difference in time lying down in stall; cows in SAND herds were lying for 12.01 (11.22; 10.10 to 12.34$) \mathrm{h} / \mathrm{d}$, and cows in MAT herds were lying for $11.66(10.78 ; 9.67$ to 11.90$) \mathrm{h} / \mathrm{d}$. In addition, there was no significant base effect on time up in alley and time up milking. Base effects were apparent for time up feeding and time standing up in stall. Cows in MAT herds spent significantly longer time standing up in stall $(1.61 \mathrm{~h} / \mathrm{d})$ than cows in SAND herds $(P=0.002)$. Time up feeding was significantly greater in cows in SAND herds $(P=0.03)$.

Behavior during a stall use session was further examined (Table 5). Although time lying down in stall was similar between cows in MAT and SAND herds, the manner in which the overall lying time was obtained showed interesting differences. Cows in MAT herds entered the stall for significantly fewer mean (back-transformed mean, 95\% confidence limits) stall use sessions per day at $6.92(5.95 ; 4.83$ to 7.08$)$, compared with 7.57 $(7.60 ; 6.41$ to 8.79$)$ sessions in cows in SAND herds $(P=$ $0.03)$. There were no overall significant differences in the numbers of lying and standing bouts performed during the stall use sessions, but there were differences in the distribution of lying bout durations between the 2 groups (Figure 1). Median lying bout duration for all cows was $57 \mathrm{~min}$. Therefore, we examined differences in the proportion of lying bouts $>60 \mathrm{~min}$, referred to as long lying bouts. Cows in SAND herds had a signifi- 
Table 3. Least square means and SE for background data for cows selected and filmed on 6 herds using mattresses (MAT) and 6 herds using sand bedding (SAND).

\begin{tabular}{|c|c|c|c|}
\hline & MAT & SAND & $P$ \\
\hline Cows (no.) & 60 & 60 & \\
\hline Parity & $2.7(0.3)$ & $3.0(0.3)$ & 0.36 \\
\hline $\begin{array}{l}\text { Days in milk } \\
\text { at day of visit }\end{array}$ & $161.4(21.1)$ & 146.9 & 0.62 \\
\hline $\begin{array}{l}\text { Last DHIA recorded } \\
\text { daily milk yield }(\mathrm{kg} / \mathrm{d})\end{array}$ & $39.0(2.4)$ & $40.7(2.5)$ & 0.60 \\
\hline $\begin{array}{l}\text { Last DHIA predicted/actual } \\
\text { ME } 305^{1} \text { milk yield }(\mathrm{kg})\end{array}$ & $12,293\left(\begin{array}{ll}413 & 9\end{array}\right)$ & $12,670(419.6)$ & 0.53 \\
\hline
\end{tabular}

${ }^{1}$ ME305 = Mature equivalent 305-d milk yield.

cantly greater proportion of long lying bouts $(0.61)$ than did cows in MAT herds (0.49) $(P=0.03)$. Mean (backtransformed mean; 95\% confidence limits) standing bout duration was significantly longer in cows in MAT herds at $0.19(0.19 ;-1.06$ to 1.44$) \mathrm{h} / \mathrm{d}$ compared with $0.10(0.09 ;-1.33$ to 1.51$) \mathrm{h} / \mathrm{d}$ for cows in SAND herds $(P=0.002)$.

\section{Daily Time Budgets-Lameness Effect}

Table 6 details the daily activity time budgets for all cows by locomotion score. Data were available from a total of 73 nonlame cows (locomotion score $=1$ ), 37 slightly lame cows (locomotion score $=2$ ), and 10 moderately lame cows (locomotion score $=3$ ) across all herds and both stall base types. Severely lame cows (locomotion score $=4$ ) were not included in the study and accounted for only $1.8 \%$ of the study population.

There were no significant differences in time up milking and time up feeding between locomotion scores. Slightly lame cows had similar time lying down in stall compared with nonlame cows, but time standing up in stall was elevated, and time up in alley reduced significantly. These trends were repeated in moderately lame cows to the extent that mean (back-transformed mean; 95\% confidence limits) time down in stall was significantly reduced to $10.59(9.75 ; 8.60$ to 10.90$) \mathrm{h} / \mathrm{d}$. These cows had significantly fewer stall standing bouts $(P=0.005)$ and numerically fewer mean stall use sessions at 5.40/d compared with $7.54 / \mathrm{d}$ in nonlame cows and $7.14 / \mathrm{d}$ in slightly lame cows.
Figure 2 shows how daily activity patterns of cows vary by locomotion score between MAT and SAND herds. Activity patterns are consistent in cows in SAND herds across all locomotion scores with little variation. Nonlame cows in MAT herds behave similar to all cows in SAND herds, apart from a small but significantly higher time up in stall. In contrast, cows in MAT herds that are slightly lame and moderately lame show the modifications in behavior described in the previous section. As time standing up in stall increases, time spent performing other activities is reduced. Time up milking is largely unchanged, but time up in alley is significantly reduced $(P<0.05)$. Moderately lame cows in MAT herds had significantly $(P=0.003)$ fewer mean (backtransformed mean; 95\% confidence limits) number of stall use sessions at $4.62(4.33 ; 3.10$ to 5.55$)$ compared with moderately lame cows in SAND herds at 8.50 (8.60; 7.12 to 10.09 ).

Figures 3 and 4 visually explain the interaction between stall base and the influence of lameness determined by locomotion score in more detail. Figure 3 charts the distribution of standing bout duration for cows in MAT and SAND herds by locomotion score. The distribution is similar between the 2 groups for nonlame cows, but for slightly lame cows, we start to see a greater proportion of standing bouts $>30 \mathrm{~min}$ in duration in MAT herds compared with SAND herds. For moderately lame cows, the distribution is markedly different, with many standing bouts $>1 \mathrm{~h}$ in duration in cows in MAT herds but not in SAND herds.

Table 4. Mean (back-transformed mean; $95 \%$ confidence limits) daily activity patterns (h/d) for 60 cows in 6 herds using mattresses (MAT) and for 60 cows in 6 herds using sand bedding (SAND).

\begin{tabular}{llll}
\hline Daily activity & MAT & SAND & $P$ \\
\hline Time lying in stall & $11.66(10.78 ; 9.67$ to 11.90$)$ & $12.01(11.22 ; 10.10$ to 12.34$)$ & 0.56 \\
$\begin{array}{l}\text { Time standing } \\
\text { in stall }\end{array}$ & $3.44(3.41 ; 2.16$ to 4.65$)$ & $1.83(1.56 ; 0.16$ to 2.97$)$ & 0.002 \\
Time up in alley & $2.27(1.66 ; 0.42$ to 2.89$)$ & $2.34(1.76 ; 0.50$ to 3.01$)$ & 0.66 \\
Time up feeding & $4.08(3.99 ; 2.82$ to 5.16$)$ & $4.65(4.52 ; 3.34$ to 5.69$)$ & 0.03 \\
Time up milking & $2.58(2.40 ; 1.23$ to 3.58$)$ & $3.21(2.95 ; 1.77$ to 4.13$)$ & 0.37 \\
\hline
\end{tabular}


Table 5. Mean (back-transformed mean; $95 \%$ confidence limits) daily stall use activity for 60 cows in 6 herds using mattresses (MAT) and for 60 cows in 6 herds using sand bedding (SAND).

\begin{tabular}{lccc}
\hline Daily activity & MAT & SAND & $P$ \\
\hline Number of stall use sessions & $6.92(5.95 ; 4.83$ to 7.08$)$ & $7.57(7.60 ; 6.41$ to 8.79$)$ & 0.03 \\
Number of lying bouts & $11.50\left(10.46 ;{ }^{1} 9.11\right.$ to 11.8$)$ & $10.28\left(8.86 ;{ }^{1} 7.37\right.$ to 10.36$)$ & 0.55 \\
Mean lying bout duration (h/d) & $1.16\left(1.22,{ }^{1} 1.05\right.$ to 1.39$)$ & $1.29\left(1.35 ;{ }^{1} 1.18\right.$ to 1.52$)$ & 0.25 \\
Proportion of lying bouts $>60$ min & $0.49\left(0.53 ;{ }^{1} 0.45\right.$ to 0.60$)$ & $0.61\left(0.65 ;{ }^{1} 0.57\right.$ to 0.72$)$ & 0.03 \\
Number of standing bouts in stall & $19.23\left(18.39 ;{ }^{1} 16.6\right.$ to 20.2$)$ & $17.98\left(16.56 ;{ }^{1} 14.60\right.$ to 18.53$)$ & 0.11 \\
Mean standing bout duration (h/d) & $0.19(0.19 ;-1.06$ to 1.44$)$ & $0.10(0.09 ;-1.33$ to 1.51$)$ & 0.002 \\
\hline
\end{tabular}

${ }^{1}$ Mean in parenthesis is a least square mean when variable was not transformed.

Figure 4 examines the effect of stall base type and locomotion score on time up in stall. For nonlame cows, there was a small but significant increase $(P=0.05)$ in mean (back-transformed mean; 95\% confidence limits) time up in stall from $1.70(1.49 ; 0.28$ to 2.71$) \mathrm{h} / \mathrm{d}$ in SAND herds to $2.43(1.97 ; 0.75$ to 3.19$) \mathrm{h} / \mathrm{d}$ in MAT herds. This difference increased markedly for slight and moderately lame cows. Time up in stall for slightly lame cows in MAT herds was $4.39(4.34 ; 2.95$ to 5.73$) \mathrm{h} / \mathrm{d}$ compared with $2.07(1.71 ; 0.41$ to 3.01$) \mathrm{h} / \mathrm{d}$ in SAND herds $(P<0.001)$, and for moderately lame cows in MAT herds, time up in stall was $6.11(4.62 ; 3.09$ to 6.16$) \mathrm{h} /$ $\mathrm{d}$ compared with $1.80(1.50 ;-0.80$ to 3.81$) \mathrm{h} / \mathrm{d}$ in SAND herds $(P=0.02)$.

\section{DISCUSSION}

The findings of this study suggest that behavioral differences related to stall use exist between cows housed in MAT compared with SAND free stall herds. These differences may have relevance to the signifi- cantly lower prevalence of lameness in SAND herds found in this study and previously by Cook (2003).

\section{Stall Design and Stall Use Behavior}

Stall use behavior may be influenced by stall design and dimensions (Anderson, 2002; Gaworski et al., 2003; Nordlund and Cook, 2003) and degree of overstocking (Wierenga and Hopster, 1990; Leonard et al., 1996). There were no significant differences in stall design and degree of overstocking between the SAND and MAT herds in this study. There were trends for lower divider rails that were higher above the stall surface in SAND herds and higher rear curb heights in MAT herds. Lower divider rails located $0.46 \mathrm{~m}$ above the stall surface have been associated with problems in stalls that require side lunging (Nordlund et al., 2001), and high rear curbs have been linked with higher rates of lameness in free stalls in Europe (Faull et al., 1996), suggesting that both of these factors may be important in some circumstances. However, curb height failed to

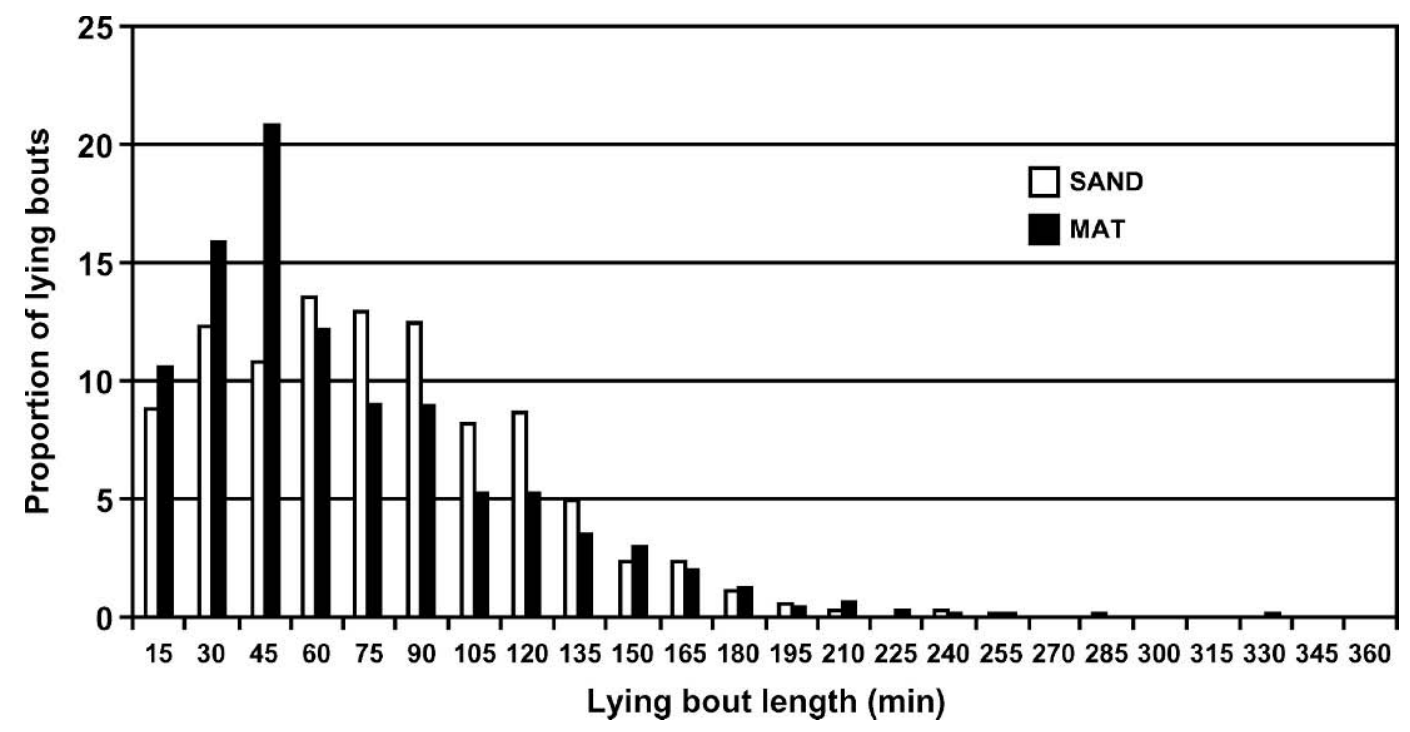

Figure 1. Distribution of lying bouts as a proportion of all bouts for 60 cows in SAND (sand-bedded free stall) herds and for 60 cows in MAT (rubber crumb-filled geotextile mattress free stall) herds by bout duration using 15-min increments. 
Table 6. Mean (back-transformed mean; $95 \%$ confidence limits) daily activity patterns for 120 cows with different locomotion scores $(1=$ non lame, 2 = slight lameness, and $3=$ moderate lameness) for all herds and both stall base types (MAT [mattress] and SAND [sand-based bedding]).

\begin{tabular}{|c|c|c|c|}
\hline & \multicolumn{3}{|c|}{ Locomotion score } \\
\hline Cows (no.) & 73 & 37 & 10 \\
\hline Stall use sessions per day (no.) & $7.54(7.32 ; 6.24$ to 8.40$)$ & $7.14(6.81 ; 5.70$ to 7.92$)$ & $5.40(6.10 ; 4.85$ to 7.35$)$ \\
\hline Lying bouts per day (no.) & $11.03\left(10.77 ;^{1} 9.85\right.$ to 11.69$)$ & $11.32\left(11.01{ }^{1} 9.71\right.$ to 12.32$)$ & $8.30\left(7.20 ;^{1} 4.69\right.$ to 9.72$)$ \\
\hline Time lying in stall $(\mathrm{h} / \mathrm{d})$ & $11.99^{\mathrm{a}}(11.90,10.82-12.98)$ & $11.87^{\mathrm{a}}(11.47 ; 10.37$ to 12.57$)$ & $10.59^{\mathrm{b}}(9.75 ; 8.60$ to 10.90$)$ \\
\hline Stall standing bouts per day (no.) & $18.59^{\mathrm{a}}\left(18.60 ;^{1} 17.35\right.$ to 19.85$)$ & $19.76^{\text {a }}\left(19.89 ;^{1} 18.20\right.$ to 21.59$)$ & $14.50^{\mathrm{b}}\left(13.94 ;^{1} 10.76\right.$ to 17.11$)$ \\
\hline Time up feeding $(\mathrm{h} / \mathrm{d})$ & $4.51(4.32 ; 3.21$ to 5.43$)$ & $4.23(4.09 ; 2.96$ to 5.21$)$ & $3.82(4.31 ; 3.12$ to 5.49$)$ \\
\hline Time up milking $(\mathrm{h} / \mathrm{d})$ & $2.87(2.61 ; 1.50$ to 3.72$)$ & $2.94(2.56 ; 1.43$ to 3.70$)$ & $2.93(2.83 ; 1.60$ to 4.05$)$ \\
\hline
\end{tabular}

${ }^{\mathrm{a}, \mathrm{b}}$ Different superscripts indicate significant difference across rows at $P<0.05$, based on Fisher's protected least significant difference.

${ }^{1}$ Mean in parenthesis is a least square mean when variable was not transformed.

remain in the model in this study as a significant fixed effect. Stalls in both groups met standards generally acceptable for a 636-kg cow (Nordlund and Cook, 2003). However, the stalls did not meet suggested space guidelines for cows $>700 \mathrm{~kg}$, which were common in this study. In particular, neck rails were generally not located immediately above the brisket board as is recommended for mattress stalls (Nordlund and Cook, 2003), but were positioned on average only $1.64 \mathrm{~m}$ from the rear curb along the horizontal in both SAND and MAT herds. This location might have influenced the type of standing behavior in the stalls in both groups.

Few studies have documented daily lying times for cows housed on sand-bedded free stalls. Tucker et al.

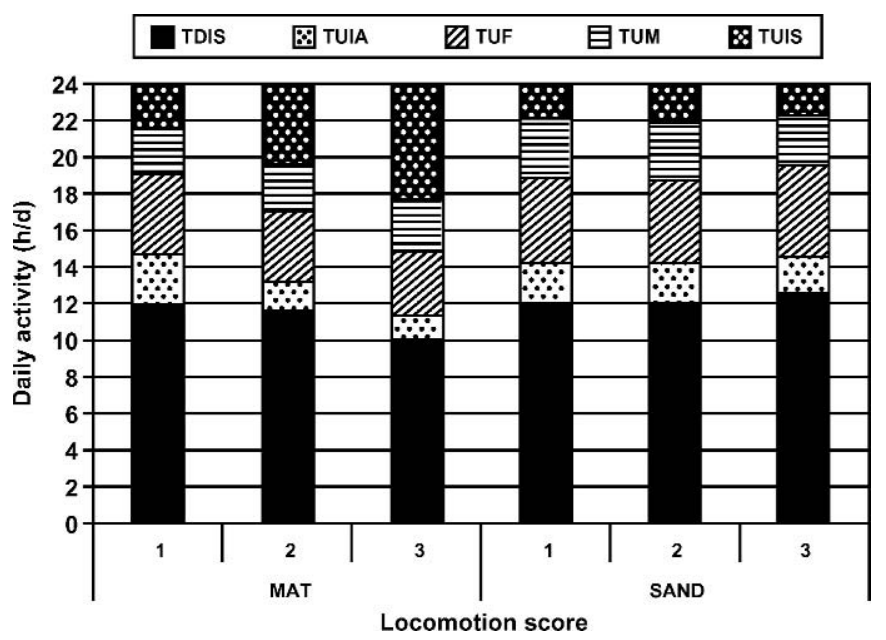

Figure 2. Daily time budgets for time lying down in stall (TDIS), time standing up in stall (TUIS), time up in alley (TUIA), time up feeding (TUF), and time up milking (TUM) in 73 nonlame (locomotion score $=1$ ), 37 slightly lame (locomotion score $=2$ ), and 10 moderately lame (locomotion score $=3$ ) cows in 6 MAT (rubber crumb-filled geotextile mattress free stall) and 6 SAND (sand-bedded free stall) herds.
(2003) found mean lying times of $10.9 \mathrm{~h} / \mathrm{d}$ on sand and $14.3 \mathrm{~h} / \mathrm{d}$ on a rubber crumb mattress in one study, and Manninen et al. (2002) found lying times in sand stalls $<7.5 \mathrm{~h} / \mathrm{d}$ compared with 10.8 to $12.9 \mathrm{~h} / \mathrm{d}$ in concrete stalls with lots of straw and stalls with rubber mats. Reduced sand stall usage has been documented in extremes of temperature (Wagner-Storch et al., 2003), and refusal or reluctance to use sand stalls in some cows is also reported in research environments (Manninen et al., 2002; Tucker et al., 2003). The inclusion of data from a few cows that refused to use the stalls or used them very little contributed to the low lying times reported in the latter 2 studies. These data appear to contradict the finding in the field that new free stall barns with sand have a higher satisfaction score than new mattress barns with respect to cow comfort among herd owners (Bewley et al., 2001) and that lameness prevalence in herds with sand stalls is lower (Cook, 2003). Managing loose-bedded sand stalls is challenging, and there are several problems that may arise turning a comfortable stall into a stall that is unusable (Cook, 2001). Such factors might have influenced lying times and stall acceptance in these research environments.

\section{Differences in Time Budgets and Stall Use Between Stall Base Types}

In modern commercial free stall facilities, it would appear that, on average, high yielding dairy cows lie down for approximately $12 \mathrm{~h} / \mathrm{d}$, feed for around $4.5 \mathrm{~h} /$ $\mathrm{d}$, stand and drink in the alleys for $2.3 \mathrm{~h} / \mathrm{d}$, milk for 2.6 to $3.2 \mathrm{~h} / \mathrm{d}$ (depending on milking frequency), and stand in the stalls for around 1.8 to $3.4 \mathrm{~h} / \mathrm{d}$, depending on circumstances.

Although time lying down in the stall was similar between the 2 groups of herds at around $12 \mathrm{~h} / \mathrm{d}$, there 

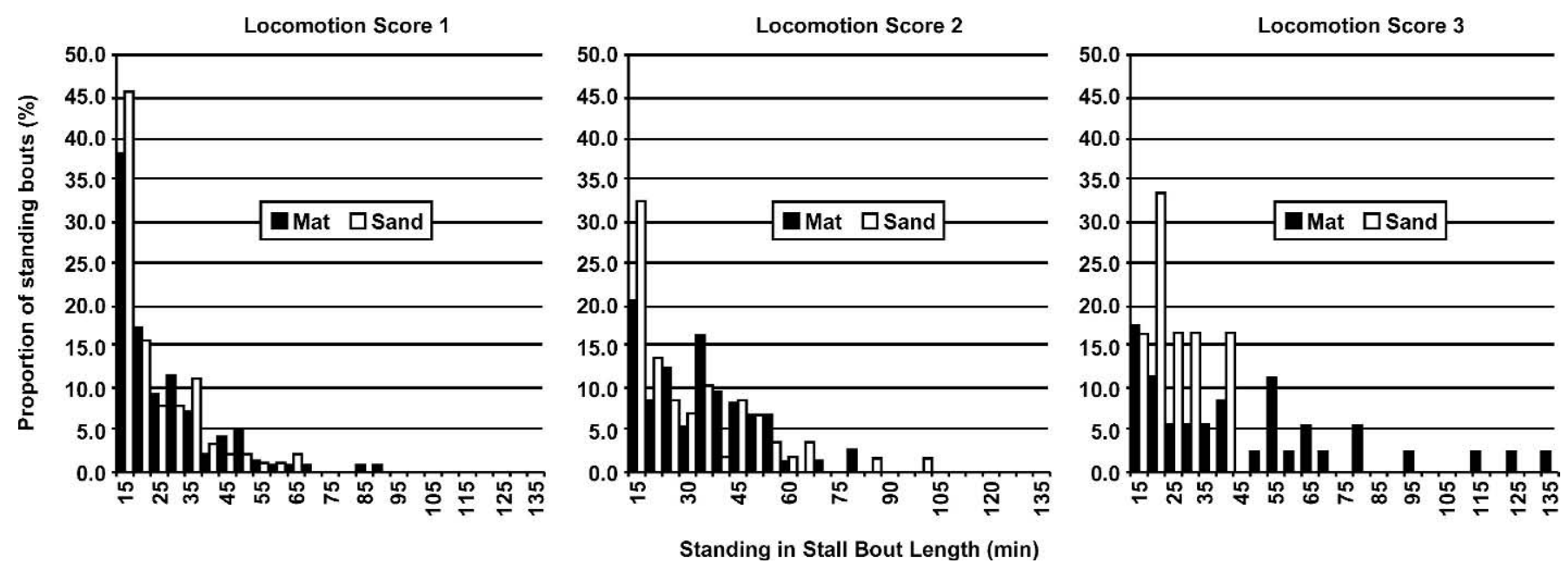

Figure 3. Distribution of stall standing bout duration by locomotion score $(1=$ nonlame, $2=$ slightly lame, and $3=$ moderately lame $)$ for 60 cows in SAND (sand-bedded free stall) herds and 60 cows in MAT (rubber crumb-filled geotextile mattress free stall) herds by proportion of all standing bouts for all cows within locomotion score class in 10-min increments.

were subtle differences in the way in which cows obtained their total number of lying hours. Cows in SAND herds had a significantly greater mean number of stall use sessions at 7.57/d than did cows in MAT herds at 6.92 sessions/d. There were no significant differences in total number of lying and standing bouts, and there was no difference in the mean duration of lying bout between the 2 groups of cows. However, the continuous monitoring technique used in this study enabled each lying bout to be accurately recorded, compared with interval scanning techniques, which miss many short standing bouts during a stall use session. There were

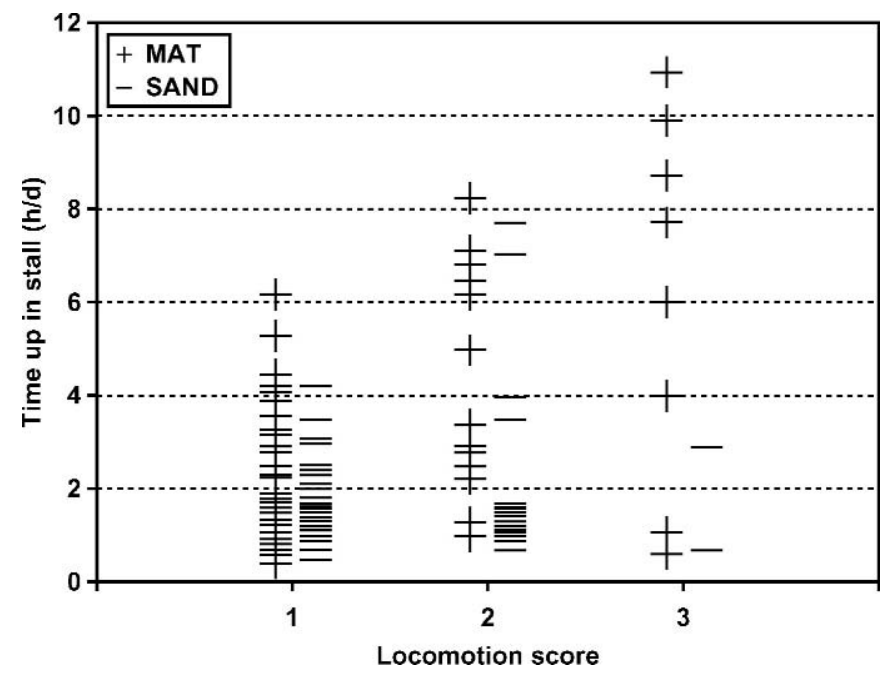

Figure 4. Interaction between locomotion score $(1=$ nonlame, $2=$ slightly lame, and $3=$ moderately lame) and base (MAT or SAND) and its effect on time spent standing up in stall (h/d) for 120 total cows. differences in the distribution pattern of lying bouts by duration between cows in SAND herds and MAT herds (Figure 1). Cows in MAT herds had significantly fewer long lying bouts compared with cows in SAND herds, suggesting that surface cushion deficits may lead to cows growing uncomfortable sooner, triggering restlessness and standing in the stall.

Time standing up in stall for cows in MAT herds was $1.61 \mathrm{~h} / \mathrm{d}$ longer than that for cows in SAND herds. Tucker et al. (2003) also found that standing behavior on a mattress surface was more variable than was the same behavior on deep sand or sawdust stall surfaces and noted several animals with extremely high standing times. These findings may be explained by the behavior of lame cows demonstrated in the current study.

\section{Behavior Patterns in Lame Cows}

Few studies have accurately documented the behavior of lame cows. Singh et al. (1993b) and Hassall et al. (1993) used the Manson and Leaver (1988) locomotion scoring system to group cows as lame (score $\geq 3$ ) and nonlame (score $<3$ ) and compared behavioral differences between these 2 groups in free stall housing and at pasture. Lame cows lay down for longer than nonlame cows in stalls and at pasture, but the difference was only significant at pasture. Lame cows also spent more time standing in free stalls, but again the difference was not statistically significant. These studies failed to consider the effects of slight lameness in the nonlame group, which might have confused the overall findings. Juarez et al. (2003) documented increasing lying activity with increasing lameness severity after 
return from morning milking in 2 Californian herds housed in free stall barns. Unfortunately, stall bedding type is not described in either herd, and daily lying activity times were not recorded.

In contrast, in the current study, we identified a reduction in mean daily lying time in moderately lame cows on mattress free stalls but not on sand free stalls. Chaplin et al. (2000b) also identified reduced lying times and more disturbed lying behavior in a group of heifers in early lactation, housed in free stalls with bedded rubber mats, compared with a similar age group in early pregnancy that were not milked. This difference was attributed to several factors, which included the finding that the early lactation heifers suffered significantly more severe hoof lesions than did pregnant heifers. Early lactation heifers with the higher prevalence of hoof lesions also spent more time standing in stalls than did the pregnant heifer group. This change in behavior was also found in the current study, with slightly lame and moderately lame cows showing elevated daily stall standing time in MAT herds. However, this change in behavior in lame cows was not repeated in SAND herds. This is the first study to carefully examine the interaction between the severity of lameness (determined by locomotion score) and stall base type on stall use behavior. For slightly lame cows, the time standing up in stall was $2.32 \mathrm{~h} / \mathrm{d}$ greater for cows in MAT herds than for cows in SAND herds and for moderately lame cows the difference grew to $4.31 \mathrm{~h} / \mathrm{d}$ (Figure 4 ), with an increase in the proportion of standing bouts of long duration (Figure 3 ).

Clearly, the time for which a cow will lie down or stand in a free stall is a complex decision process affected by several factors. These include the behavioral need for the animal to rest, the difficulties presented by the design of the stall, and problems associated with lameness, which may modulate the ability of the cow to perform the movements of lying down and rising. In deprivation studies, cows will choose to rest rather than eat when both a place to lie down and feed are restricted, suggesting that cows aim to maintain a rather fixed number of hours lying down per day (Metz, 1985). Therefore, there must be other overriding reasons why lame cows choose to stand in a mattress stall rather than spend time standing in the alley or maintaining daily lying time. There must also be reasons why lame cows in sand stalls choose not to indulge in this change in behavior.

Several researchers have stated that cows prefer to spend more time standing on a cushioned mattressbedded free stall in preference to spending time standing elsewhere (Tucker et al., 2003; Wagner-Storch et al., 2003). Additionally, lame cows can avoid encountering aggressive dominant cows in the alley if they 'hide' in a stall (Galindo et al., 2000). Therefore, there are some perceived benefits to increased time spent standing in the stall, if it replaces time spent on concrete in an alley. Although time spent standing in the alley was significantly reduced in lame cows in MAT herds, lying time was also reduced in moderately lame cows in these herds. Sand is also a cushioned surface, but lame cows did not demonstrate this alteration in stall use behavior. Therefore, there may be other alternative explanations for the increase in stall standing behavior in cows in MAT herds, other than a preference choice between 2 types of standing surface.

The significant difference in mean stall standing time between cows in MAT herds and cows in SAND herds was due to increasing standing bout duration in slight and moderately lame cows (Figure 3). Hoof lameness is a significant cause of chronic pain in dairy cows (Whay et al., 1998), and the rear feet are most commonly affected (Russell et al., 1982). Therefore, we believe that the differences in time standing up in the stall observed may be explained by behavioral responses to pain and the desire to lie down. The process of rising and lying in the dairy cow requires a complex sequence of movements (Nordlund and Cook, 2003) and may be made more difficult by the presence of a painful foot. Perhaps sand, because of its ability to supply cushion and traction, allows cows (especially lame cows) to perform the process of lying down more easily, without fear of slipping. We propose that the fear of slipping and pain associated with rising and lying on a mattress surface for a lame cow are other possible reasons for extended bouts of standing in the stall during a stall use session.

Figure 3 describes the time budgets for daily activities for nonlame and lame cows on different stall surfaces. In MAT herds, slightly lame cows spend almost twice as long standing in the stall per day as nonlame cows, but maintained lying time at almost $12 \mathrm{~h} / \mathrm{d}$ by spending less time standing in the alley. The increase in standing time in the stall is so great in moderately lame cows in MAT herds that they have significantly fewer stall use sessions per day than equivalent cows in SAND herds (4.62 compared with 8.50) and an overall reduction in daily lying time. At least part of this time spent standing must therefore replace lying time in these individuals. The fact that there is no difference in the total number of lying and standing bouts between stall surface types reflects the desire for lame cows to maintain daily lying time in both types of environment. We believe that the increase in standing bout duration in lame cows in mattress stalls between lying bouts (Figure 3) reflects a period during which the cow is reluctant to perform the process of lying down after rising. The reduced proportion of these long standing bouts in lame cows on sand suggests that it is easier 
for them to lie down quickly, thereby maintaining daily activity patterns similar to nonlame cows.

For lame cows to maintain daily lying time, these data suggest that it may be wise to move them from mattress free stalls to loose housing on a comfortable bedded pack of straw or to pasture, where they may rise and lie down more easily.

\section{Stall Standing Behavior as a Risk Factor for Lameness}

Mean lameness prevalence was significantly lower in SAND herds at $11.1 \%$ compared with $24.0 \%$ in MAT herds. This finding is consistent with a previous lameness prevalence survey performed by one of the authors (Cook, 2003) conducted on similar herds. Several researchers have made the observation that time spent standing in the stall is an important risk factor for lameness (Leonard et al., 1994; Galindo et al., 2000; Fregonesi et al., 2002). In particular, Galindo et al. (2000) indicated that perching activity is important and that cows that spend more time perching are more likely to become lame. Time standing up in stall measured in this study included both standing with all 4 feet in the stall and perching. It should be noted, however, that when comparing stall standing behavior between cows in SAND and MAT herds, the cows in sand stalls tend to perch more because they are reluctant to stand with their rear feet on the raised rear curb, which is often sloped rather than flat. In addition, the elevation of the front feet above the rear feet during perching in a loosebedded sand stall is not equivalent to that in a mattress stall, making conclusions on the effect of perching between the 2 environments somewhat difficult. Nonlame cows spent $0.73 \mathrm{~h} / \mathrm{d}$ more standing in mattress free stalls than equivalent cows in sand free stalls. This difference was statistically significant, but we question whether it is sufficient to explain the disparity in lameness prevalence between the herds with different stall surface types. The increase in stall standing behavior observed in lame cows on mattress stalls compared with sand stalls in the current study is a more dramatic difference that may be of greater overall importance.

The increased time spent bearing weight during a stall use session might have a potentially harmful effect on the duration of the lameness event. Current hypotheses for the development of claw horn lesions involve loosening of the connection between the pedal bone and the horn capsule of the claw, with subsequent sinking of the pedal bone and compression of the tissues of the sole (Lischer et al., 2002; Tarlton et al., 2002; Cook et al., 2004). Abnormal standing activity in lame cows in stalls may exacerbate these changes, prolonging the duration of the event, which may contribute to an in- crease in lameness prevalence. It is possible that the type of stall standing behavior may be more a function of stall design and in particular neck rail location (Gaworski et al., 2003) than being driven by social factors in subordinate cows (Galindo and Broom, 2000). It is also possible that cows spend more time perching once they become lame, but this has yet to be determined.

\section{CONCLUSIONS}

This study has demonstrated that cows in sand stall herds do not modify their daily time budgets when they are lame. In contrast, lame cows in mattress stall herds spend up to $4.31 \mathrm{~h} / \mathrm{d}$ more standing in the stall. This fundamental difference in cow behavior raises questions with regard to the effect of standing in stall behavior on the duration of the lameness event, and this may, at least in part, explain the difference in herd lameness prevalence observed between SAND herds and MAT herds. However, the current study does not explain a causal link between these 2 findings.

Lying times in both sand and mattress stall herds were comparable. The relative merits and success of a particular stall surface in the types of farm in this study appear to have more to do with how lame cows behave and use the stalls rather than nonlame cows. Future behavior studies related to stall use should control for lameness if the findings are to be fully understood.

More work is needed to further investigate the onset and duration of lameness in cows and the significance and type of stall standing activity in lame and nonlame cows in different environments. The behavior of severely lame cows was not documented and must be the focus of future studies.

\section{ACKNOWLEDGMENTS}

This study was funded by grants obtained from the University of Wisconsin-Madison, School of Veterinary Medicine, Food Animal Fund and from Land O'Lakes, Inc. The authors acknowledge and appreciate the assistance of Murray Clayton, College of Agriculture and Life Sciences Statistical Consulting Service, University of Wisconsin, with the statistical analysis. We also thank Hunter Lang, David Rhoda, Mike Bradford, Robert Steiner, Jerome Gaska, Karl Burgi, Jeff Monson, and James Bailey for their assistance in selecting the herds and the farmers for their cooperation with the study.

\section{REFERENCES}

Anderson, N. 2002. Observations on cow comfort using 24 hour time lapse video. Pages 27-34 in Proc. 12th Int. Symp. Lameness in Ruminants, Orlando, FL. 
Bergsten, C., and A. H. Herlin. 1996. Sole hemorrhages and heel horn erosion in dairy cows: The influence of housing system on their prevalence and severity. Acta Vet. Scand. 37:395-408.

Bewley, J., R. W. Palmer, and D. B. Jackson-Smith. 2001. A comparison of free-stall barns used by modernized Wisconsin dairies. J. Dairy Sci. 84:528-541.

Bickert, W. G. 2000. Milking herd facilities. Pages 27-45 in Dairy Free Stall Housing and Equipment. MWPS-7, 7th ed. Midwest Plan Service, Iowa State University, Ames.

Chaplin, S. J., H. E. Ternent, J. E. Offer, D. N. Logue, and C. H. Knight. 2000b. A comparison of hoof lesions and behaviour in pregnant and early lactation heifers at housing. Vet. J. 159:147-153.

Chaplin, S. J., G. Tierney, C. Stockwell, D. N. Logue, and M. Kelly. 2000a. An evaluation of mattress and mats in two dairy units. Appl. Anim. Behav. Sci. 66:263-272.

Colam-Ainsworth, P., G. A. Lunn, R. C. Thomas, and R. G. Eddy. 1989. Behaviour of cows in cubicles and its possible relationship with laminitis in replacement dairy heifers. Vet. Rec. 125:573576.

Cook, N. B. 2001. How good is sand bedding for your cows? Hoard's Dairyman 146:667.

Cook, N. B. 2003. Prevalence of lameness among dairy cattle in Wisconsin as a function of housing type and stall surface. JAVMA 223:1324-1328.

Cook, N. B., K. V. Nordlund, and G. R. Oetzel. 2004. Environmental influences on claw horn lesions associated with laminitis and subacute ruminal acidosis (SARA) in dairy cows. J. Dairy Sci. 87:(E. Suppl.):E36-E46.

Faull, W. B., J. W. Hughes, M. J. Clarkson, D. Y. Downham, F. J. Manson, J. B. Merritt, R. D. Murray, W. B. Russell, J. E. Sutherst, and W. R. Ward. 1996. Epidemiology of lameness in dairy cattle: The influence of cubicles and indoor and outdoor walking surfaces. Vet. Rec. 139:130-136.

Fregonesi, J. A., F. Flower, T. Vittie, C. B. Tucker, and D. M. Weary. 2002. Rubber flooring affects behavior of dairy cows, especially animals with hoof injuries. J. Dairy Sci. 85(Suppl. 1):28. (Abstr.)

Galindo, F., and D. M. Broom. 2000. The relationships between social behaviour of dairy cows and the occurrence of lameness in three herds. Res. Vet. Sci. 69:75-79.

Galindo, F., D. M. Broom, and P. G. G. Jackson. 2000. A note on possible link between behaviour and the occurrence of lameness in dairy cows. Appl. Anim. Behav. Sci. 67:335-341.

Gaworski, M. A., C. B. Tucker, D. M. Weary, and M. L. Swift. 2003. Effects of stall design on dairy cattle behavior. Pages 139-146 in Proc. Dairy Housing Conf., Fort Worth, TX. Amer. Soc. Agric. Eng., St Joseph, MI.

Greenough, P. R., and J. J. Vermunt. 1991. Evaluation of subclinical laminitis in a dairy herd and observations on associated nutritional and management factors. Vet. Rec. 128:11-17.

Haley, D. B., A. M. de Passille, and J. Rushen. 2001. Assessing cow comfort: Effect of two types and two tie stall designs on the behaviour of lactating dairy cows. Appl. Anim. Behav. Sci. 71:105-117.

Hassall, S. A., W. R. Ward, and R. D. Murray. 1993. Effects of lameness on the behavior of cows during the summer. Vet. Rec. 132:578-580.

Juarez, S. T., P. H. Robinson, E. J. DePeters, and E. O. Price. 2003. Impact of lameness on behavior and productivity of lactating Holstein cows. Appl. Anim. Behav. Sci. 83:1-14.
Leonard, F. C., J. M. O’Connell, and K. J. O’Farrell. 1994. Effect of different housing conditions on behaviour and foot lesions in Friesian heifers. Vet. Rec. 134:490-494.

Leonard, F. C., J. M. O'Connell, and K. J. O'Farrell. 1996. Effect of overcrowding on claw health in first-calved Friesian heifers. Br. Vet. J. 152:459-472.

Lischer, C. H., J. P. Ossent, M. Raber, and H. Geyer. 2002. Suspensory structures and supporting tissues of the third phalanx of cows and their relevance to the development of typical sole ulcers (Rusterholz ulcers). Vet. Rec. 151:694-698.

Manninen, E., A. M. de Passillé, J. Rushen, M. Norring, and H. Saloniemi. 2002. Preferences of dairy cows kept in unheated buildings for different kinds of cubicle flooring. Appl. Anim. Behav. Sci. 75:281-292.

Manson, F. J., and J. D. Leaver. 1988. The influence of concentrate amount on locomotion and clinical lameness in dairy cattle. Anim. Prod. 47:185-190.

Metz, J. H. M. 1985. The reaction of cows to a short-term deprivation of lying. Appl. Anim. Behav. Sci. 13:301-307.

Nordlund, K. V., and N. B. Cook. 2003. A flowchart for evaluating dairy cow free stalls. Bovine Pract. 37:89-96.

Nordlund, K., S. Peek, T. Bennett, K. Emery, and J. Gaska. 2001 Inches from disaster: Mastitis and injury problems associated with free stall modifications in a large dairy herd. Pages 296300 in Proc. 2nd Int. Symp. Mastitis Milk Quality, Vancouver, Canada.

Russell, A. M., G. J. Rowlands, S. R. Shaw, and A. D. Weaver. 1982. Survey of lameness in British dairy cattle. Vet. Rec. 111:155-160.

SAS/STAT User's Guide, Version 8. 1999. SAS Inst., Inc., Cary, NC.

Singh, S. S., W. R. Ward, K. Lautenbach, J. W. Hughes, and R. D. Murray. 1993a. Behaviour of first lactation and adult dairy cows while housed and at pasture and its relationship with sole lesions Vet. Rec. 133:469-474.

Singh, S. S., W. R. Ward, K. Lautenbach, and R. D. Murray. 1993b. Behaviour of lame and normal dairy cows in cubicles and in a straw yard. Vet. Rec. 133:204-208.

Tarlton, J. F., D. E. Holah, K. M. Evans, S. Jones, G. R. Pearson, and A. J. F. Webster. 2002. Biomechanical and histopathological changes in the support structures of bovine hooves around the time of calving. Vet. J. 163:196-204.

Tucker, C. B., D. M. Weary, and D. Fraser. 2003. Effects of three types of free stall surfaces on preferences and stall usage by dairy cows. J. Dairy Sci. 86:521-529.

Vokey, F. J., C. L. Guard, H. N. Erb, and D. M. Galton. 2001. Effects of alley and stall surfaces on indices of claw and leg health in dairy cattle housed in a freestall barn. J. Dairy Sci. 84:2686-2699.

Wagner-Storch, A. M., R. W. Palmer, and D. W. Kammel. 2003. Factors affecting stall use for different free stall bases. J. Dairy Sci. 86:2253-2266.

Weary, D. M., and I. Taszkun. 2000. Hock lesions and free stall design. J. Dairy Sci. 83:697-702.

Wells, S. J., A. M. Trent, W. E. Marsh, and R. A. Robinson. 1993. Prevalence and severity of lameness in lactating dairy cows in a sample of Minnesota and Wisconsin dairy herds. JAVMA 202:78-82.

Whay, H. R., A. E. Waterman, A. J. F. Webster, and J. K. O'Brien. 1998. The influence of lesion type on the duration of hyperalgesia associated with hindlimb lameness in dairy cattle. Vet. J. 156:23-29.

Wierenga, H. K., and H. Hopster. 1990. The significance of cubicles for the behaviour of dairy cows. Appl. Anim. Behav. Sci. 26:309-337. 